\title{
Experimental Study on Two Beds Adsorption Chiller with Regeneration
}

\author{
Abdual Hadi N. Khalifa \\ Technical College,Baghdad ,Iraq \\ Tel: 964-790-185-8234 E-mail:ahaddi58@yahoo.com
}

Fawziea M. Hussein

Technical College,Baghdad ,Iraq

Tel: 964-790-115-3916

E-mail:Fawizea_Material@yahoo.com

Faeza M. Hadi

Foundation of Techinal Education Iraq

Tel: 964-790-492-5826 E-mail:faizam2001@yahoo.com

Received: April 25, 2011

Accepted: June 20, 2011

doi:10.5539/mas.v5n4p43

\begin{abstract}
This work is devoted to investigate the setup, charging, and the influence of the key variables on the performance of a 1.5 tons capacity two bed adsorption chiller. The beds $(66.7 \mathrm{c} \mathrm{m} \times 52.4 \mathrm{~cm} \times 23.5 \mathrm{~cm}$ each) functions as methanol generators. The using of two generators is to build a nearly continuous adsorption-desorption cycle, by allowing the generators to work alternatively either adsorbing or desorbing the medium. The switching between desorption and adsorption phases was achieved by a simple manual electric control system. The adsorption chiller was driven by hot water, with a temperature range of 70 to $100^{\circ} \mathrm{C}$. Active carbon-methanol adsorption pair was used in this study. The chiller was charged by $11 \mathrm{~kg}$ of active carbon and $2.2 \mathrm{~kg}$ of methanol, giving an initial concentration of $\left(0.1966 \mathrm{~kg} \mathrm{CH}_{3} \mathrm{OH} / \mathrm{kg} \mathrm{AC}\right)$. It was found that using the mass recovery process increases the initial concentration of methanol in the desorption generator; hence, improving the COP and SCP of the cycle. The COP of this adsorption chiller was about 0.301 , while the SCP was about $0.3532 \mathrm{~kW} / \mathrm{kg}_{\mathrm{AC}}$, at an outdoor temperature of $25^{\circ} \mathrm{C}$. Eventually a mass of $200 \mathrm{~kg}$ of water could be chilled from $10^{\circ} \mathrm{C}$ to about $7{ }^{\circ} \mathrm{C}$ in about $14 \mathrm{~min}$.
\end{abstract}

Keywords: Solar, Adsorption, Refrigeration, Thermally driven cycle, Cooling

\section{Introduction}

The use of absorption refrigeration cycle commenced efficient solar energy and waste heat utilization. Many innovative adsorption cycles have been designed and tested in the last twenty years. The merits of such cycles are its simplicity in design and manufacturing. Although various adsorption systems have been developed and tested. Since adsorption systems can be operated with no moving parts and without the need for rectifier or solution pump, the cost of adsorption systems is relatively lower than the absorption systems. Also, adsorption system works at relatively low temperatures, namely, in the range of $70^{\circ} \mathrm{C}$ to $100^{\circ} \mathrm{C}$. Solar energy utilization in solar cooling faces some difficulties including its low energetic conversion efficiency and the strong impact of the environmental factors on its performance. The ambient temperature, solar radiation and wind speed are among these environmental variations. Since the COP of the conventional system (about 2.5-3) is much greater than that of the adsorption cycle (about 0.1-0.3), E. E. Anyanwu and N.V.Oguke, (2005). Hildbr and C. Dind (2004) developed an adsorption icemaker in which water was used as refrigerant and ice was produced within the evaporator. In early 1980's Tchernev (1982) carried out an investigation of adsorption refrigeration with zeolite-water pair. Grenier and Pons (1988) presented a solar adsorption air conditioning system with 20 solar panels and zeolite-water working pair. Since early 1980s, the work on silica gel-water systems gained popularity and lot of work was carried out mainly in Japan. In an effort to utilize solar energy, Critoph (1986) have studied the performance limitations of adsorption cycles for solar cooling. They concluded that, in general, activated carbon-methanol combination was preferable for solar cooling, giving the best performance achievable in a single stage cycle. Pons (1986) concluded that solid sorption systems could be the basis for efficient solar-powered refrigerators. They developed a prototype with activated carbon-methanol pair. Ortel (1997) used methanol with silica gel instead of water, so that the system could operate at an evaporating temperature below $0^{\circ} \mathrm{C}$. Li and Sumathy (1999) have presented the description and operation of a solar-powered ice-maker with the solid adsorption pair of activated carbon and methanol using basic adsorption cycle. Amar (2006) presented a 
solar adsorption icemaker by using flat plate collector, where the same collector, beside it's functionality as a generator it also collects the solar radiation; it was of rectangular parallel shape. A new hybrid system of solar powered water heater and adsorption ice-maker using AC-methanol pair, has been studied by Wang (2000). The working principle is a combination of a solar water heater and an adsorption refrigerator. Headley (1994) constructed a charcoal- methanol adsorption refrigerator powered by concentrating solar collectors, but the solar COP was very low (about 0.02). In the University of Technology in Iraq, Hassan (2008) presented a theoretical and experimental steady of a hybrid adsorption refrigeration system. Ali (2010) studied experimentally and theoretically the performance of an adsorption air conditioner, the unit consists of two beds, each bed is built from two concentrating copper tube.

This paper concern with the design and performance study of a two bed adsorption chiller, a Methanol- active carbon is used as a working pair. An electrical boiler was used as a heat source to the generator to simulate solar heating. A continuous operation refrigeration cycle is achieved by six steps; each step is controlled by a simple electrical circuit.

\section{Apparatus description}

An adsorption chiller unit was built to study the effect of its performance key variables. The chiller consists of two generators, a condenser and an evaporator. An electrical boiler was used as a heat source to the generator to simulate solar heating. Each generator was constructed from three heat exchangers, with 36 copper tubes, $(16 \mathrm{~mm}$ diameters). The three heat exchangers were connected together by $U$ tube connections to each single generator. Activated carbon type (NORIT PK 1-3) has build particle size of $3.15 \mathrm{~mm}$, of apparent density of $290 \mathrm{~kg} / \mathrm{m}^{3}$, Iodine number 800 and Ash content 3\%. The activated carbon was heated in the furnace with a temperature of $250^{\circ} \mathrm{C}$ for one day, before it was inserted between the heat exchangers fins. A screen of mesh was used to hold the active carbon in place. A metal box made of mild steel which can hold a maximum pressure of 3.5 bar maximum, is used to hold the generator.

The two generators were connected by a $25.6 \mathrm{~mm}$ diameter copper tube and two way solenoid valve $\mathrm{S}_{2}$. This connection is used during the regeneration phase in which heat and mass exchange takes place between the generators, resulting in pressure equalization. Each generator is connected to the condenser through a $16 \mathrm{~mm}$ diameter copper tube and two solenoid valves $\mathrm{S}_{3}$ and $\mathrm{S}_{4}$. The low pressure side of each generator is connected to the evaporator through two solenoid valves $\mathrm{S}_{5}$ and $\mathrm{S}_{6}$. Figure 1 shows the adsorption chiller with its accessories.

A tube in tube heat exchanger is used as the unit evaporator through which the refrigerant (methanol) is passes in the inner tube while the water flows the outer tube.

\subsection{Adsorption chiller cycles:}

The continuous operation refrigeration cycle is achieved by six steps; each step is controlled by a simple electrical circuit.

The first process: As generator $\left(\mathrm{G}_{1}\right)$ receives hot water, its pressure increases, desorbing the methanol. Vapour methanol leaving generator $\left(G_{1}\right)$ condenses in the condenser. The solenoid valves $S_{2}, S_{4}$ and $S_{6}$ are closed while $\mathrm{S}_{3}$ and $\mathrm{S}_{5}$ are opened. The condensate passes through an expansion valve and its pressure falls from $\mathrm{G}_{1}$ generator pressure, at (35-40) $\mathrm{kPa}$, to the $\mathrm{G}_{2}$ generator pressure, at about $5 \mathrm{kPa}$. The saturation temperature is about $0^{\circ} \mathrm{C}$. As the methanol extracts heat from cold water, it evaporates and flows to generator $\mathrm{G}_{2}$ where it is adsorbed. In this process the desorption process is conducted in generator $\mathrm{G}_{1}$, while the adsorption process is conducted in generator $\mathrm{G}_{2}$, as shown in figure 2 the time required for this cycle is about (5) min.

The second process: Solenoid valve $S_{2}$ is opened (shown in figure 3) to extract the remaining vapor of methanol from the generator $G_{1}$ at $25 \mathrm{kPa}$ to generator $\mathrm{G} 2$ at $5 \mathrm{kPa}$ the cycle stops when both generators $\mathrm{G}_{1}$ and $\mathrm{G}_{2}$ are at about the same pressure, namely $19 \mathrm{kPa}$. The time required for this process is about (1) min.

The third process: In the process (shown in Figure 4), all solenoid valves are closed. The cooling water flows in generator $G_{1}$ preparing it to the adsorption process, while the hot water flows in generator $G_{2}$. As a result of heating, the pressure of generator $\mathrm{G}_{2}$ increases to about (35-40) $\mathrm{kPa}$ causing the methanol to desorb. The adsorption process in the generator $\mathrm{G}_{2}$ occurs at constant mass. At the end of this process the vapor methanol is accumulated in generator $\mathrm{G}_{2}$. The time required to complete this step is about (1) min.

The fourth process (shown in Figure 5), this process is just like the first process but the active generator is $\mathrm{G}_{2}$, while generator $G_{1}$ preparing to adsorption process. Methanol vapor flows through valve $S_{4}$ to condenser, then condensates at constant pressure of about (35-40) $\mathrm{kPa}$. The pressure of methanol condensate falls rapidly to evaporator pressure of $5 \mathrm{kPa}$ as it passes through the expansion valve. The cooling effect is achieved in the evaporator. Methanol vapor flows to generator $G_{1}$ through valve $S_{6}$, and adsorbed there. The time required to complete this step is about (5) $\mathrm{min}$

The fifth process: In this cycle (shown in Figure 6), the remaining vapor methanol is withdrawn from $\mathrm{G}_{2}$ to $\mathrm{G}_{1}$ as in the second cycle. In this cycle both hot water and cooled water pumps are OFF.

The sixth process: during this process (shown in Figure 7), as in third process., all solenoid valves are closed. The hot water flows in generator $\mathrm{G}_{1}$, while the cold water flows to generator $\mathrm{G}_{2}$. This process rises the pressure 
in generator $\mathrm{G}_{1}$ inhibiting vapor desorption. The time of this process is $1 \mathrm{~min}$. The total time required to achieve a complete cycle, including the sixth cycle is about (14) min. The cycle continues back to process (1).

\subsection{Key variables:}

The key parameters studied in this work are the mass of active carbon, the temperatures of hot and cooling water that used to heat and cool the generator, evaporating and condensing temperatures and finally the time required to achieve each cycle.

\section{Results and discussions:}

Figure 8 shows the cycling time for the two generators $G_{1}$ and $G_{2}$, with regeneration. It can be seen from the figure that, there are two cycles, cycle (A-B-C-D-1-2-3-4), which is referred to cycle one, and cycle (4-5-6-7-D-E-F-H), which referred to cycle two. As it can be seen, from the figure, that generator $\mathrm{G}_{1}$ is at higher pressure and temperature, and it is susceptible to desorption process. While generator $\mathrm{G}_{2}$ is at low pressure, and it is susceptible to adsorption process.

As generator $G_{1}$ is heated, the methanol desorbs (process A-B-C) and its vapour flows to the condenser, expansion valve and evaporator, through valves $\mathrm{S}_{5}, \mathrm{~S}_{3}, \mathrm{~S}_{1}$ and $\mathrm{E}_{\mathrm{v}}$. These valves are opened during this process as shown in figure 2. The generator $\mathrm{G}_{1}$ are kept at constant pressure Pc throughout desorption phase. Meanwhile generator $G_{2}$ possesses an adsorption process. As more and more methanol is adsorbed in $G_{2}$ its pressure increases (points 1,2 and 3 ). When $G_{1}$ reaches point $C$ and $G_{2}$ reaches point 3 , a mass recovery process started by opening valvesS $S_{2}$ bringing the two generates to the same pressure $\left(\mathrm{P} 4\right.$ and $\left.\mathrm{P}_{\mathrm{D}}\right)$. At points $(4, \mathrm{D})$, the functions of the two generators are switched, $\mathrm{G}_{2}$ is now possess at desorption process, while $\mathrm{G}_{1}$ possess adsorption process. As $G_{2}$ receives hot water, the methanol desorbs and its pressure rises from $P_{4}$ to $P_{5}$ at point 5 then, the valves opened to allow methanol vapor to condensate. Meanwhile, generator $\mathrm{G}_{1}$ pressure falls, as a result of receiving cold water, from $P_{D}$ to $P_{E}$, commencing the adsorption process. Again at points 6 of $G_{2}$ and $F$ of $G_{1}$ the mass recovery process started and the pressure of the two generators are equalized at $\mathrm{P}_{7}$ and $\mathrm{P}_{\mathrm{E}}$.

Figure 9 shows the cycling time for the two generators $G_{1}$ and $G_{2}$, without mass recovery process. The sequence of this cycle is the same as that of the cycle with the mass recovery process; the only difference is that valve $\mathrm{S}_{2}$ is kept closed during this cycle, and the function of the two generators are switched when they are at same pressure, namely at point $\mathrm{A}$. The time required to achieve such cycle is greater than that with mass recovery.

Figure 10 shows the effect of condensed methanol on the generator pressure. It can be seen from the Figure that, the reduction in generator pressure (about $42 \mathrm{kPa})$ to the evaporator pressure $(10 \mathrm{kPa})$, is not a continuous process. This is because; the amount of desorbed methanol depends on the unit pressure and generator temperature. Thus, it can be seen from the Figure that, the condensation process is achieved in four periods; two of them are achieved at nearly constant pressure. The first period that extended from about 0.26 to $0.28 \mathrm{~kg}$, is achieved at constant pressure, as an amount of $0.02 \mathrm{~kg}$ of methanol is condensed, the unit pressure tends to decrease afterword. The amount of condensed methanol during the reduction in pressure period is about, $0.03 \mathrm{~kg}$. The third period is like the first one, extends from about $0.33 \mathrm{~kg}$ to $0.38 \mathrm{~kg}$, at a pressure of $35 \mathrm{kPa}$. The amount of condensed methanol during this period is about $0.03 \mathrm{~kg}$. The last period, in which the generator pressure falls from about 35 to $10 \mathrm{kPa}$, the amount of condensate methanol is about $0.1 \mathrm{~kg}$. The total amount of methanol that condenses is about 0.48 to $0.5 \mathrm{~kg}$.

Figure 11 shows the adsorption cycle for the two beds adsorption chiller without mass recovery. The ambient temperature is $27^{\circ} \mathrm{C}$, while the generator temperature is $87^{\circ} \mathrm{C}$. It can be seen from the Figure that, there are four processes. Namely; A-B: isosteric sensible heating, B-D: isobaric desorption, D-F: isosteric sensible cooling, and F-A: isobaric adsorption.

Figure 12 shows a comparison between the theoretical and experimental analysis of an adsorption chiller with two beds (Faeza 2008). It can be seen from the Figure that theoretical cycle is represented by the solid line cycle, and the mass recovery process represented by line $3-5$. While the dotted cycle represented the real adsorption cycle. It can be seen from the figure that, there is a little discrepancy between the real and theoretical cycle, especially in the sensible heating line and sensible cooling line. At the beginning of the cycle, the sensible heating line departs from the isosteric line. The remaining three real processes are very close to that of the theoretical process. Generally it can be said that, the theoretical results are consistent with the experimental results.

\section{Conclusions}

1-Two beds adsorption unit can give continue cooling effect, contrary to single bed adsorption unit.

2- Using the mass recovery process increases the pre desorption concentration, of methanol, in the desorption generator, and hence, improving the cycle $\mathrm{COP}$ and SCP.

3-The optimum COP and SCP obtained in this work is 0.403 and 0.5238 respectively, when the evaporator temperature is $0{ }^{\circ} \mathrm{C}$, condensing temperature is $40^{\circ} \mathrm{C}$, cold water temperature of $25^{\circ} \mathrm{C}$ and hot water is $80^{\circ} \mathrm{C}$. 


\section{References}

Ali H. Jabar. (2010). Experimental study of waste heat adsorption air conditioning cycle. M.Sc. thesis Submitted to Council of Technical College/Baghdad .

Amar S. A, (2006). Design, construction and performance of solar powered ice maker. M.Sc. thesis, Submitted to the Department of Machines and Equipment of the University Of Technology.

Critoph, R. E.; Vogel, R.; Oct 1986, Possible adsorption pairs for use in solar cooling. Int. J. Ambient Energy (United Kingdom), Vol. 7, No. 4; pp. 183-190.

E. E. Anyanwu, and N. V. Oguke. (2005). Thermodynamic design procedure for solid adsorption solar refrigerator. Mechanical engineering department, Federal university of technology, Renewable Energy 30, 81-96. doi:10.1016/j.renene.2004.05.005

Faeza M. Hadia. (2008). Theoretical and experimental study of two bed solar adsorption chiller with regeneration. M.Sc. thesis Submitted to Council of Technical College/Baghdad.

Grenier P, Guilleminot J.J, Meunier F, and Pons M. (1988). Solar powered solid adsorption cold store. Transaction of ASME, Journal of Sol Energy engineering, 110:192-197. doi:10.1115/1.3268256

Hassan J. Fadiel, (2008). Theoretical and experimental study of a hybrid adsorption system. M.Sc. thesis, Submitted to the Department of Machines and Equipment of the University Of Technology.

Headley AF, Mcdoom IA. (1994). Charcoal-methanol adsorption refrigerator powered by a compound parabolic concentrating solar collector. Solar Energy 53:191-7. doi:10.1016/0038-092X(94)90481-2.

Hildbrand C, Dind P, Pons M, and Buchter F. (2004). A new solar powered adsorption refrigerator with high performance. Solar Energy 77(3):311-8. doi:10.1016/j.solener.2004.05.007.

Li, Z. F. and Sumathy, K. (1999). A solar powered ice maker with the solid adsorption pair of activated carbon and methanol. International Journal of Energy Research, 23: 517- 527. doi:10.1002/(SICI)1099-114X(199905)23:6,517::AID-ER495,3.0.CO;2-B.

Ortel, K. and Fischer, M. (1997). Adsorption cooling system for cold storage using methanol and silica gel. Proceeding of international heat powered cycle conference, university of Nottingham, UK. 15,17.

Pons M, Guilleminot J.J. (1986). Design of an experimental solar powered, solid-adsorption ice maker. Transaction of ASME, Journal of Sol Energy engineering, 988;110 :192-197. 108(4):332-7.

Tchernev, D.I, (1982). Solar air conditioning and refrigeration system utilizing zeolites. Proceeding meeting of IIR commissions, EI-E2, Jerusalem, 209-215.

Wang, R. Z. (2000). An energy efficient hybrid system of solar powered water heater and adsorption ice maker. Solar energy, 68(2); 189-195. doi:10.1016/S0038-092X(99)00062-6

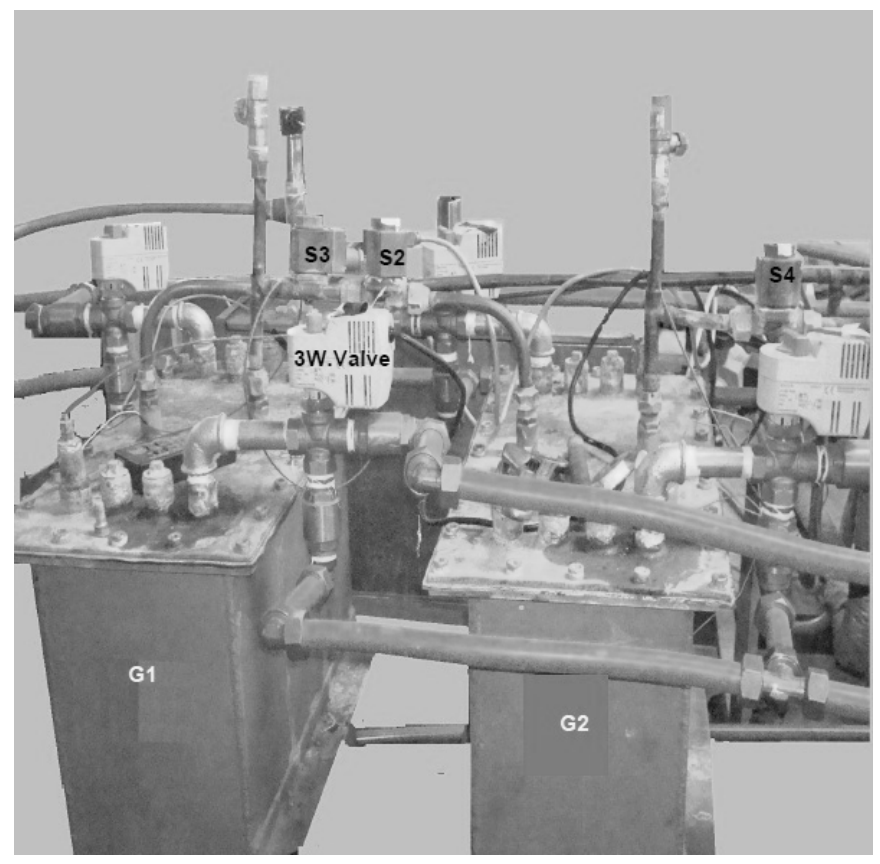

Figure 1. The adsorption chiller 


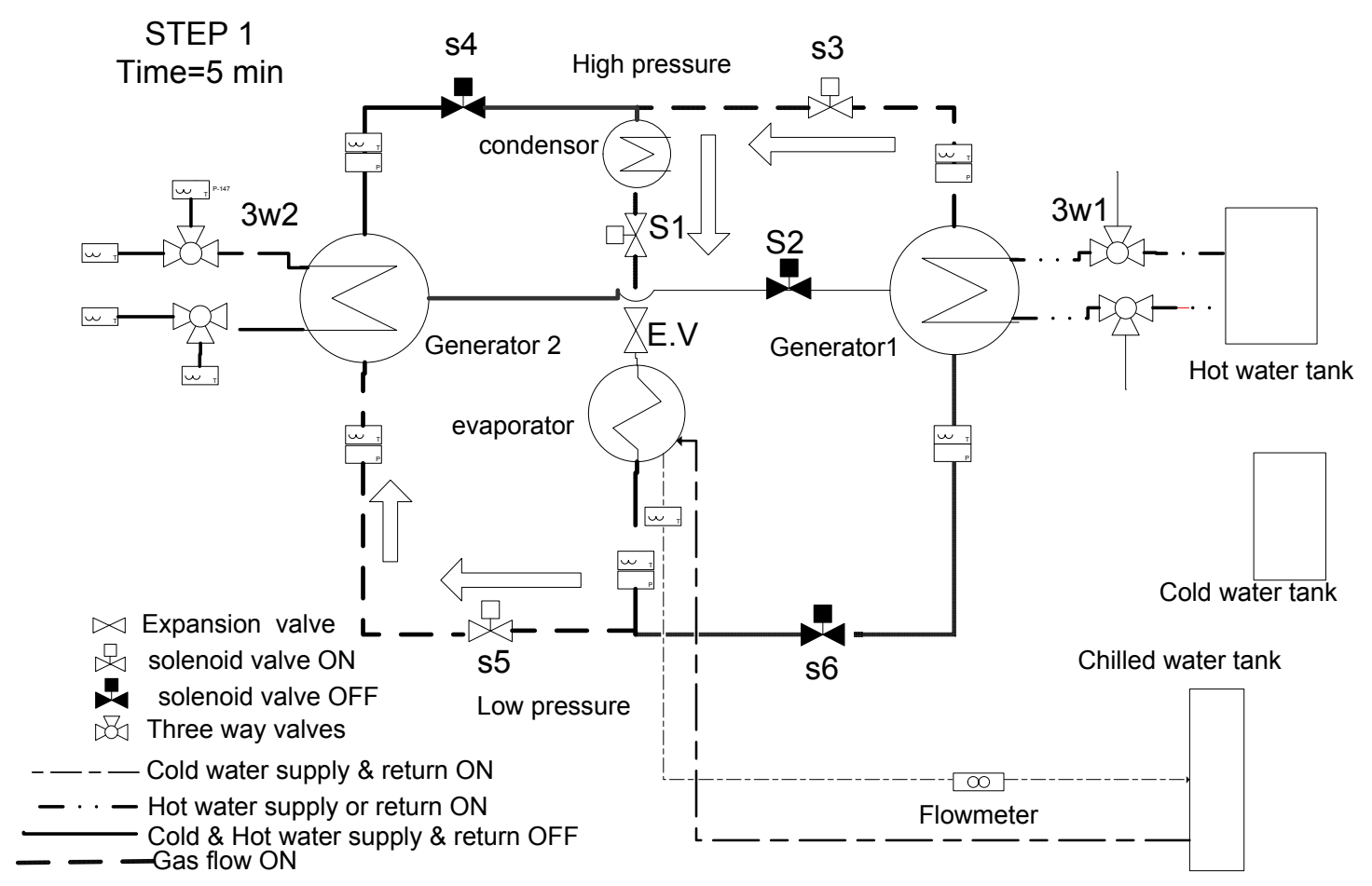

Figure 2. Refrigeration cycle operation step 1

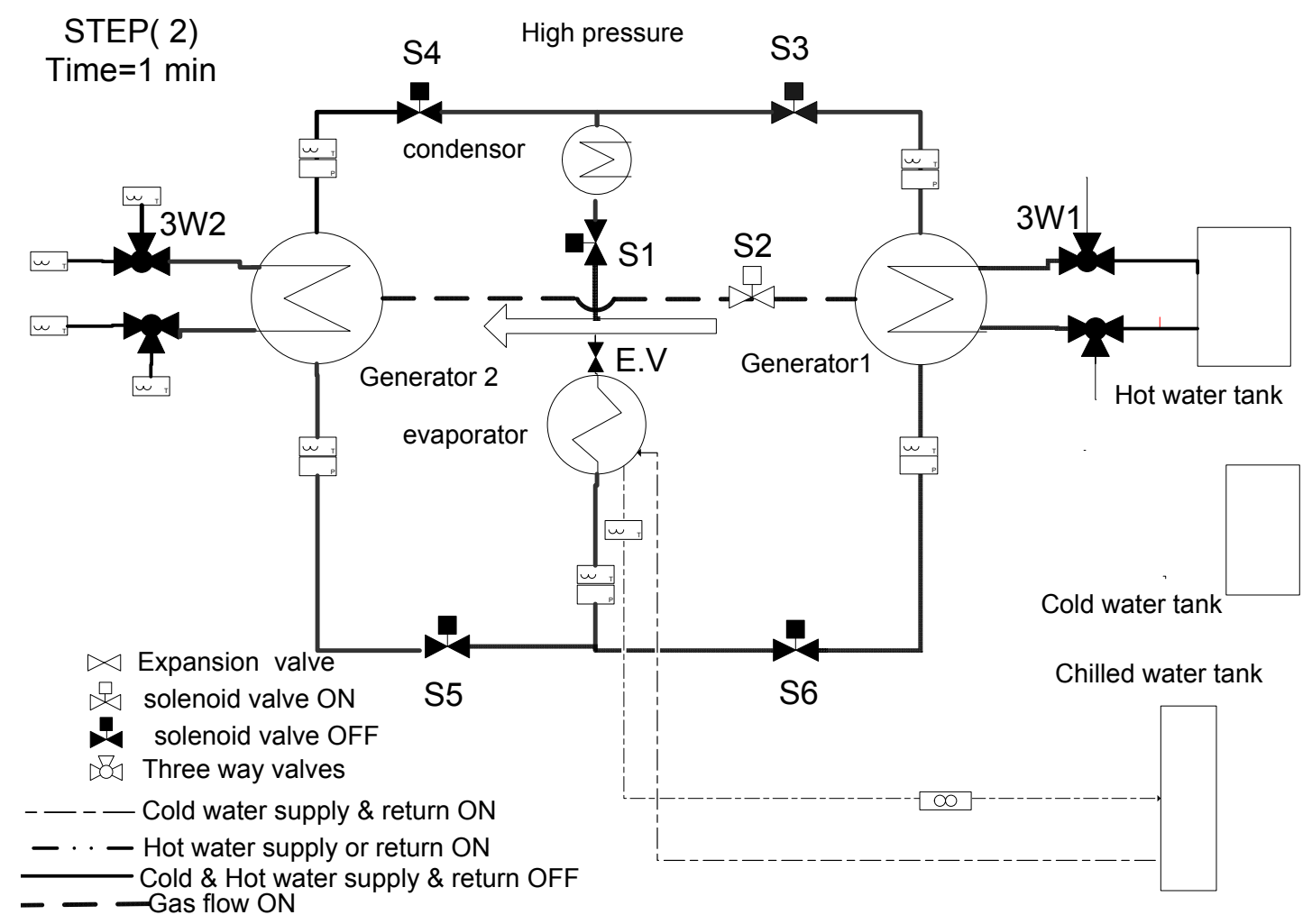

Figure 3. Refrigeration cycle operation step 2 


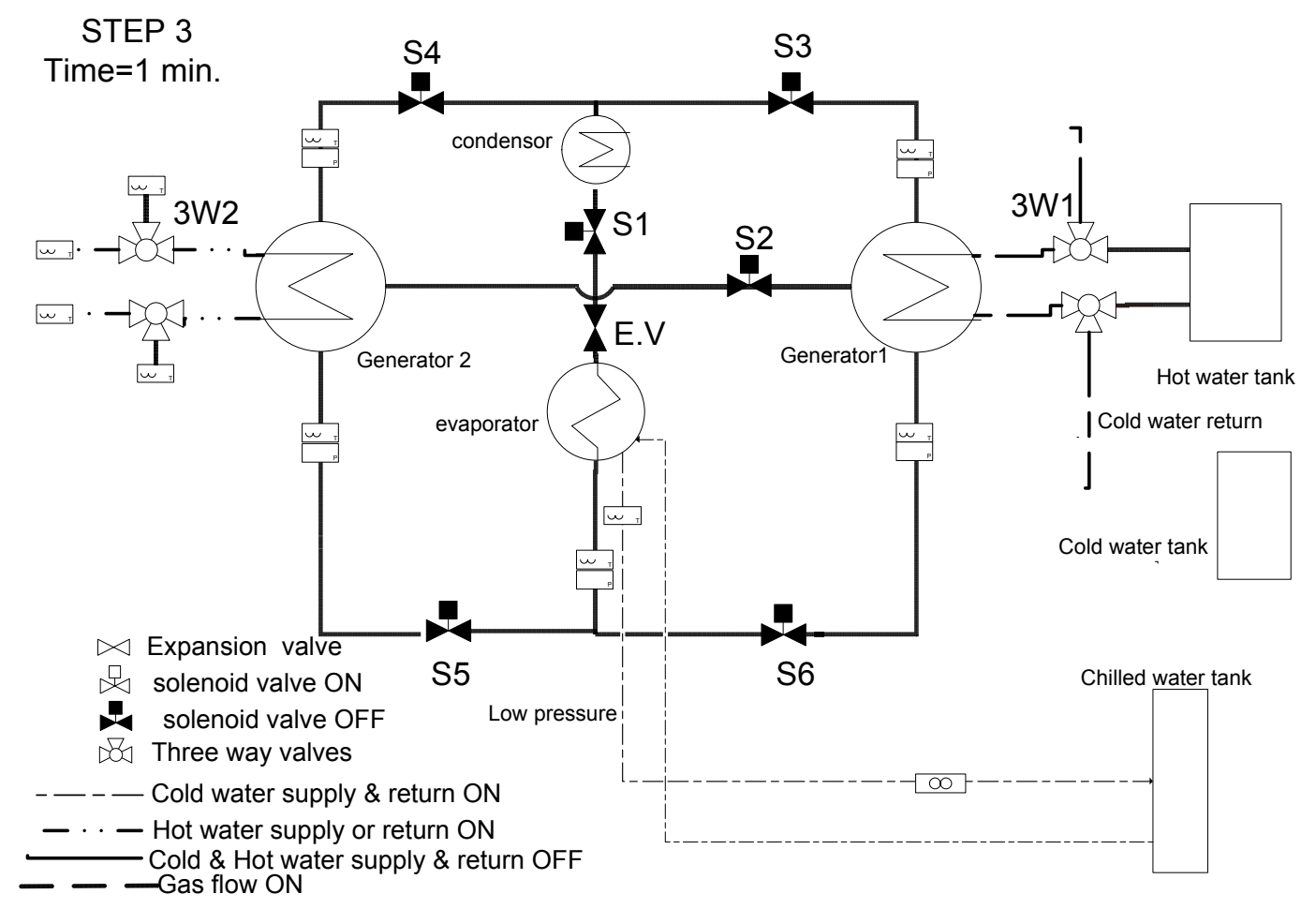

Figure 4. Refrigeration cycle operation step 3

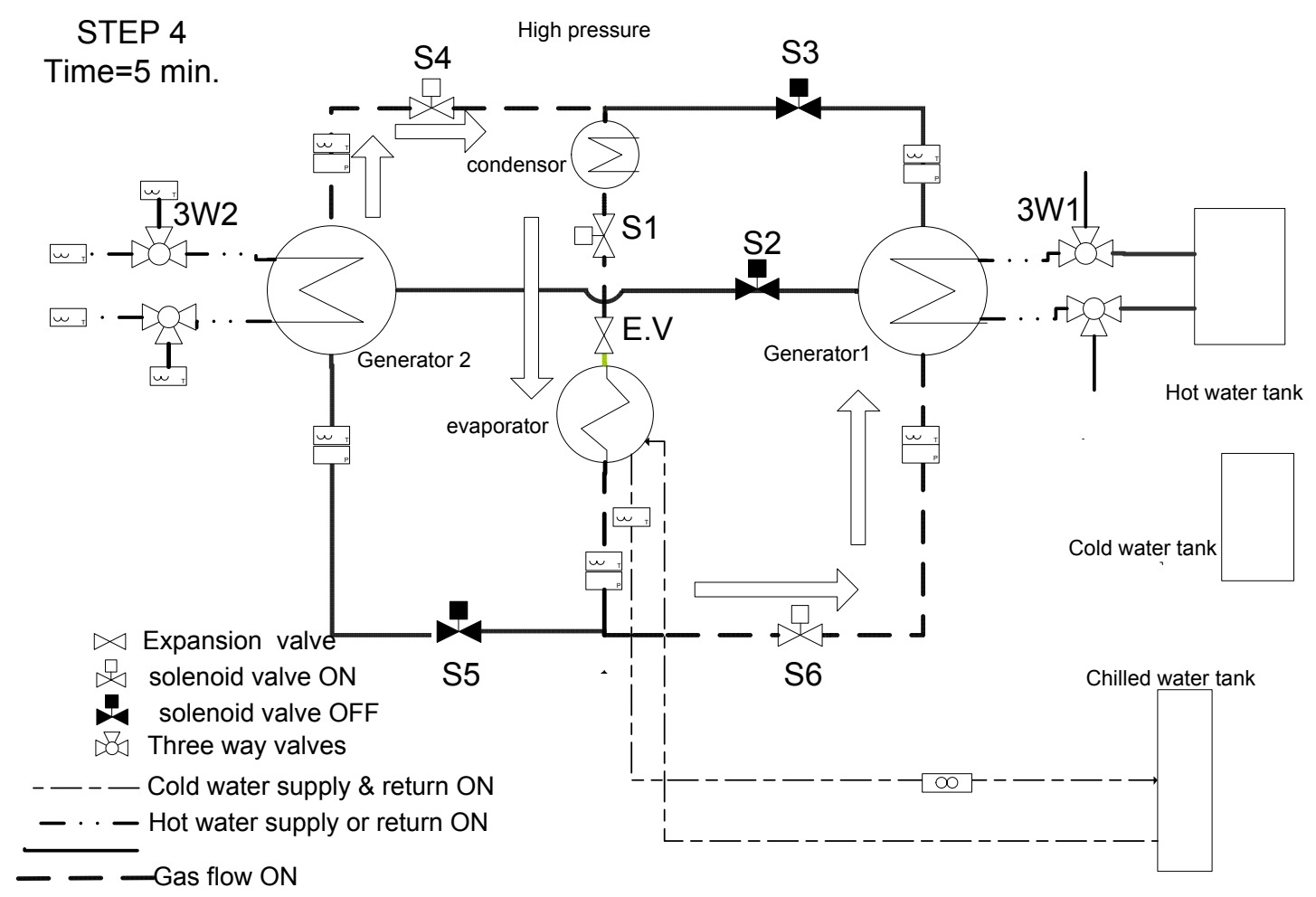

Figure 5. Refrigeration cycle operation step 4 
STEP 5

Time=1 $\mathrm{min}$.

High pressure

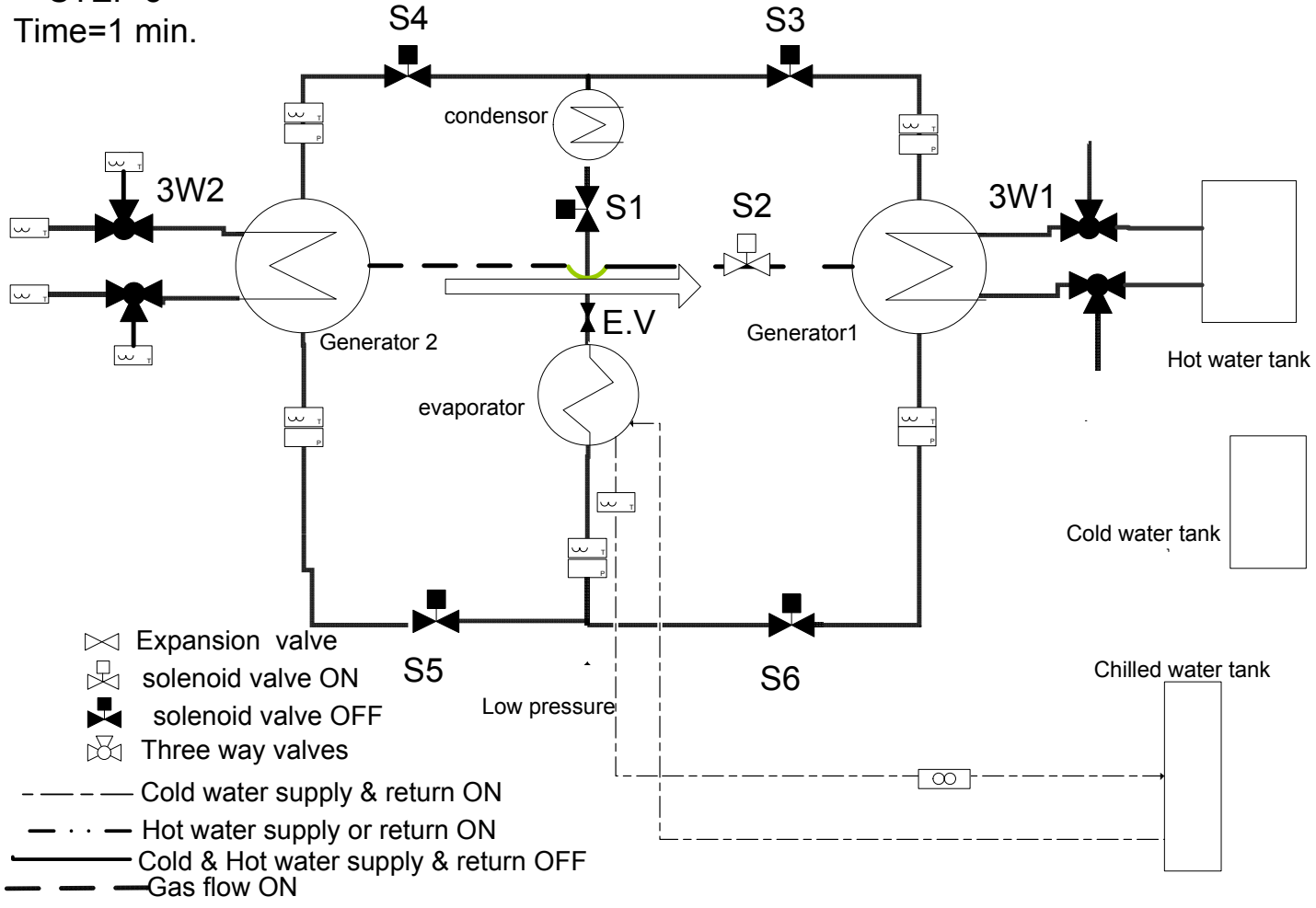

Figure 6. Refrigeration cycle operation step.5

STEP 6

Time=1 $\mathrm{min}$.

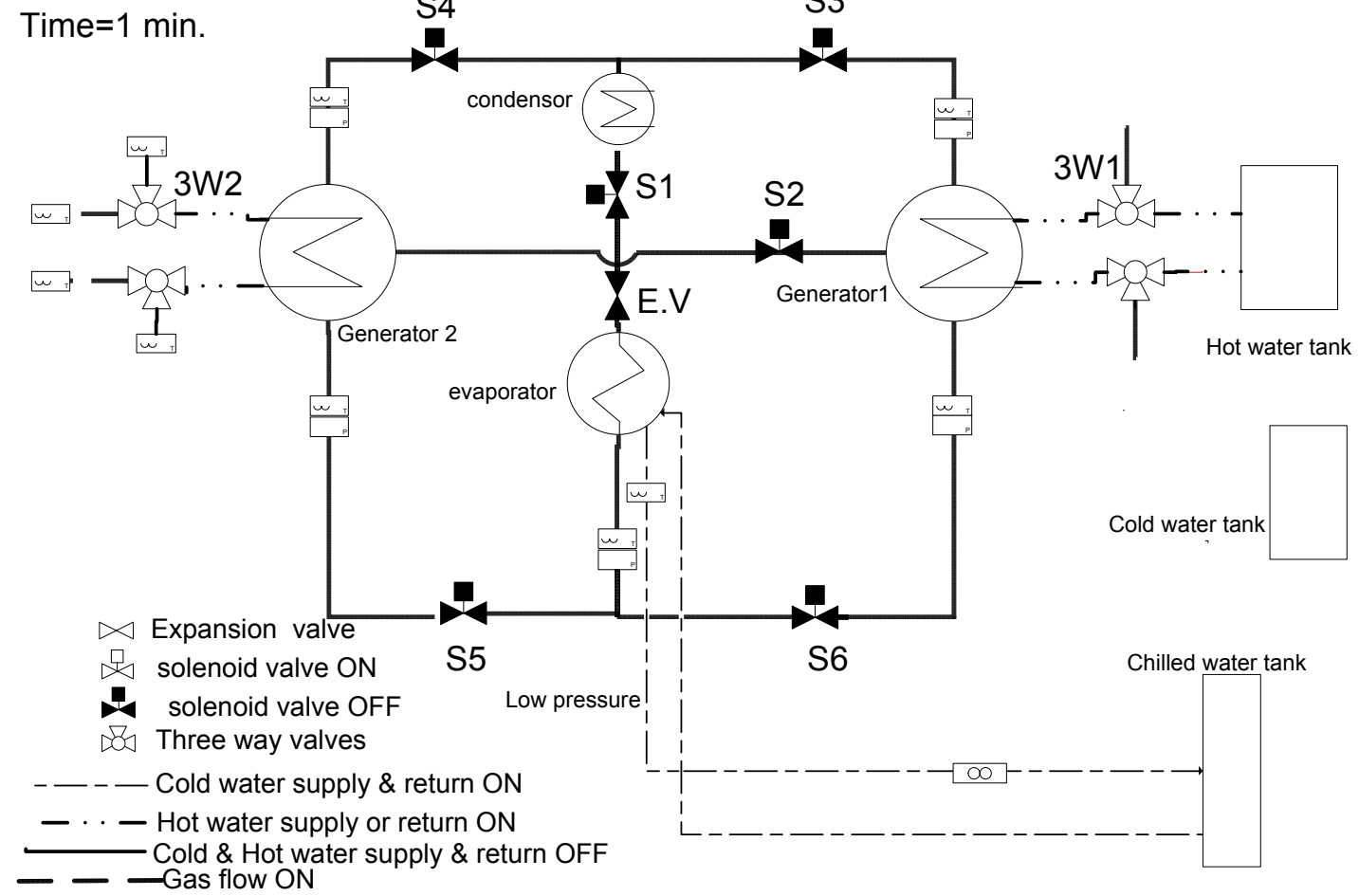

Figure 7. Refrigeration cycle operation step 6 


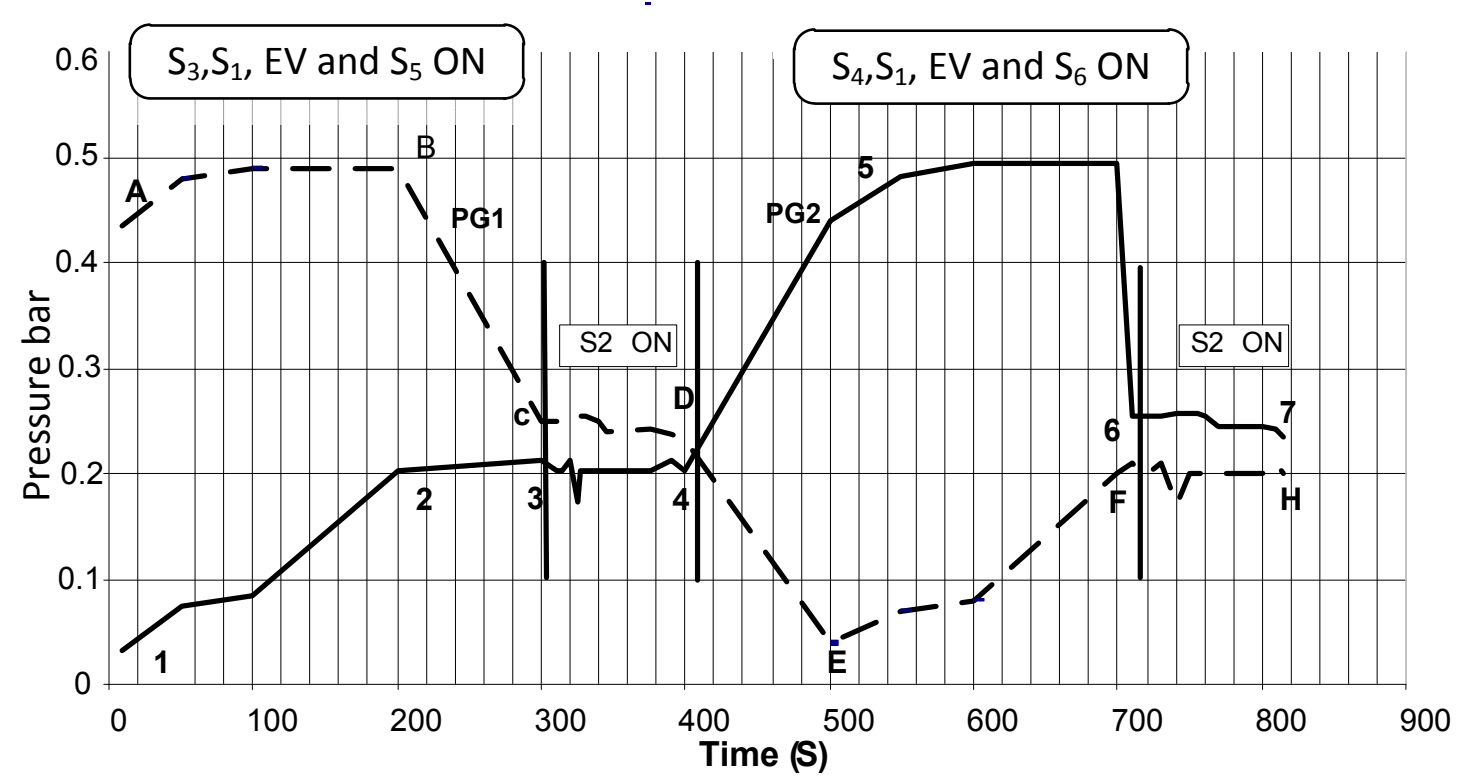

Figure 8. cycling time for adsorption chiller with mass recovery

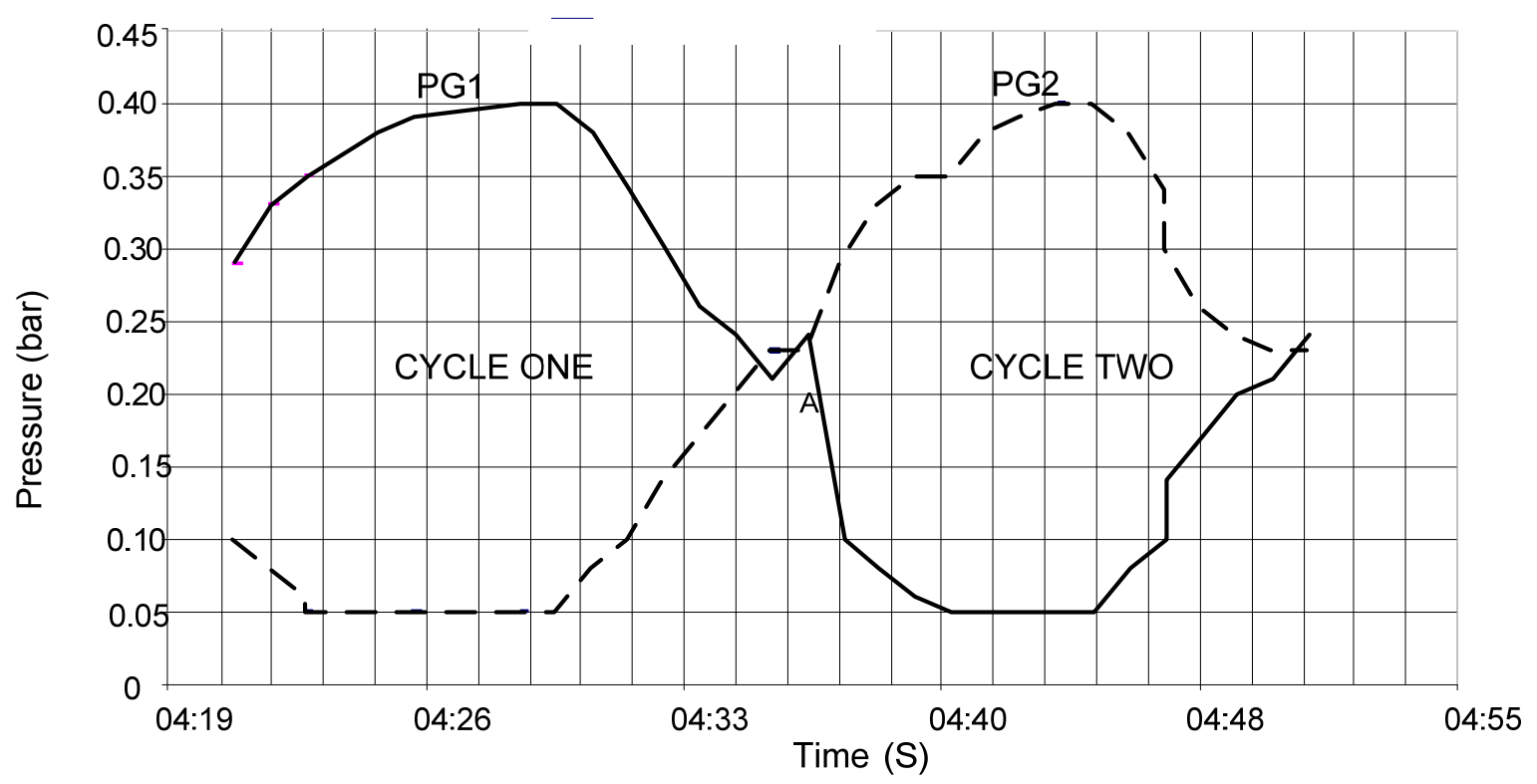

Figure 9. cycling time for adsorption chiller without mass recovery 


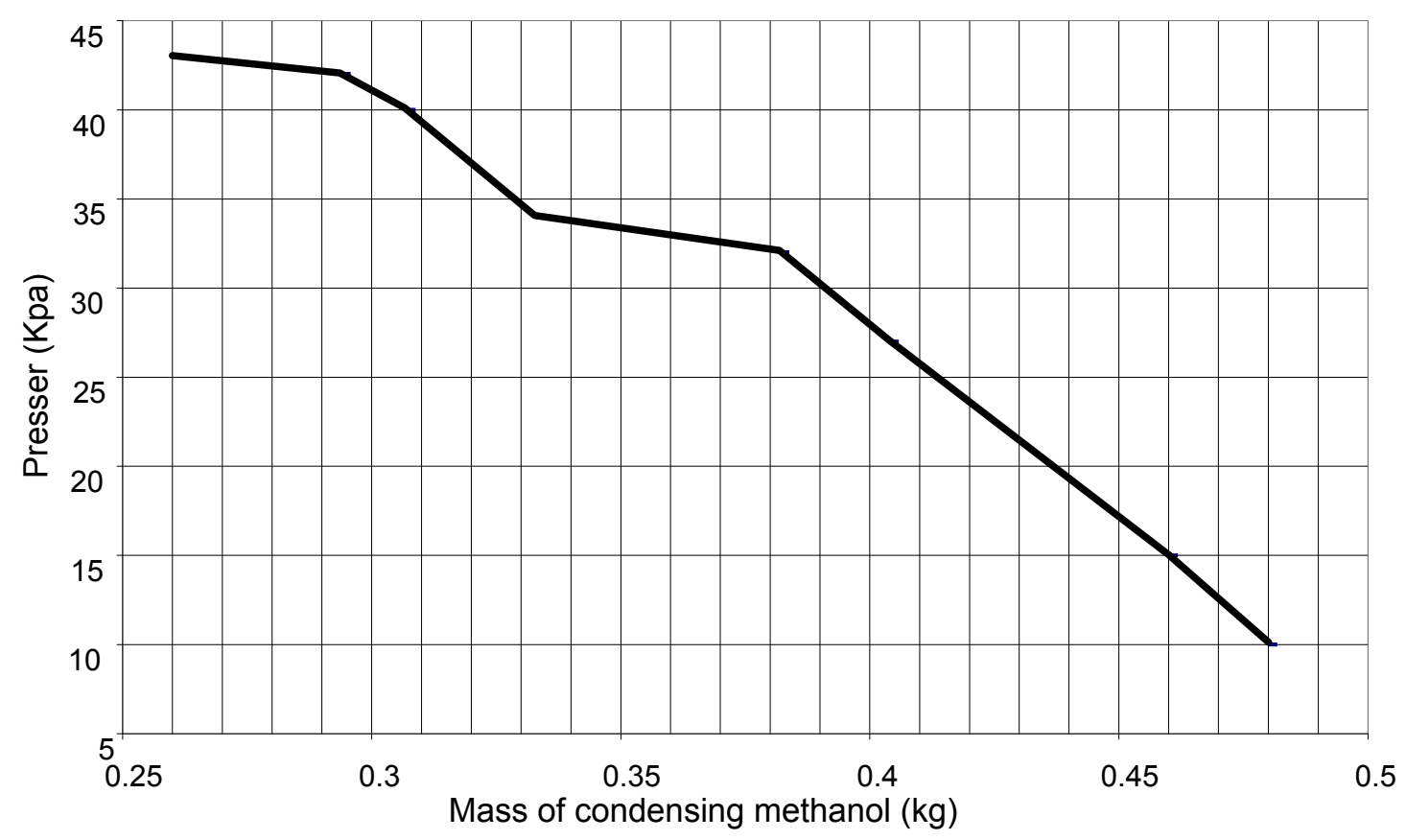

Figure 10. Relation between mass of condensed methanol and generator pressure

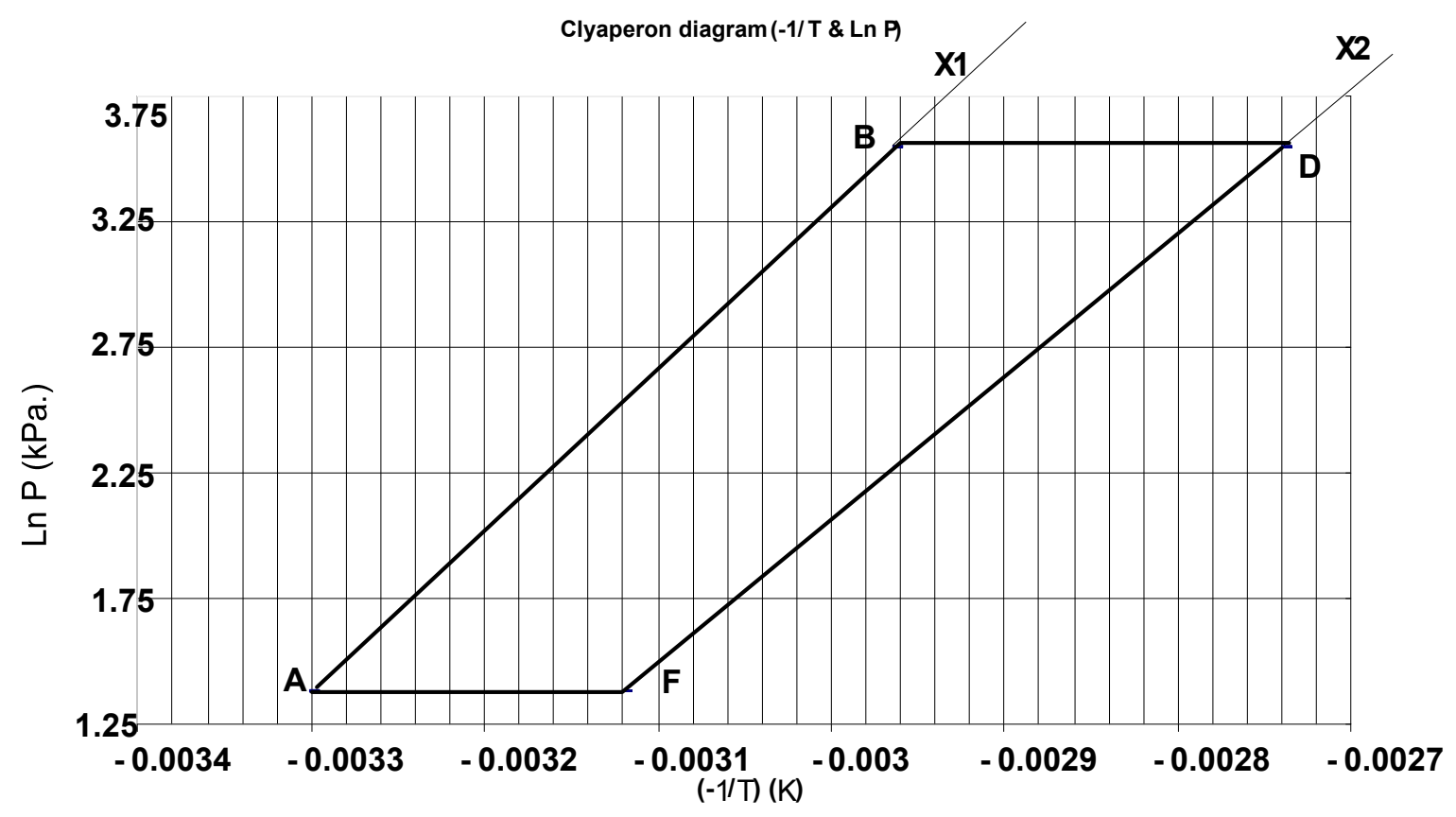

Figure 11. $P-T-x$ or Clapeyron diagram for two beds adsorption chiller Cycle without mass recovery corresponding to the experiment data 


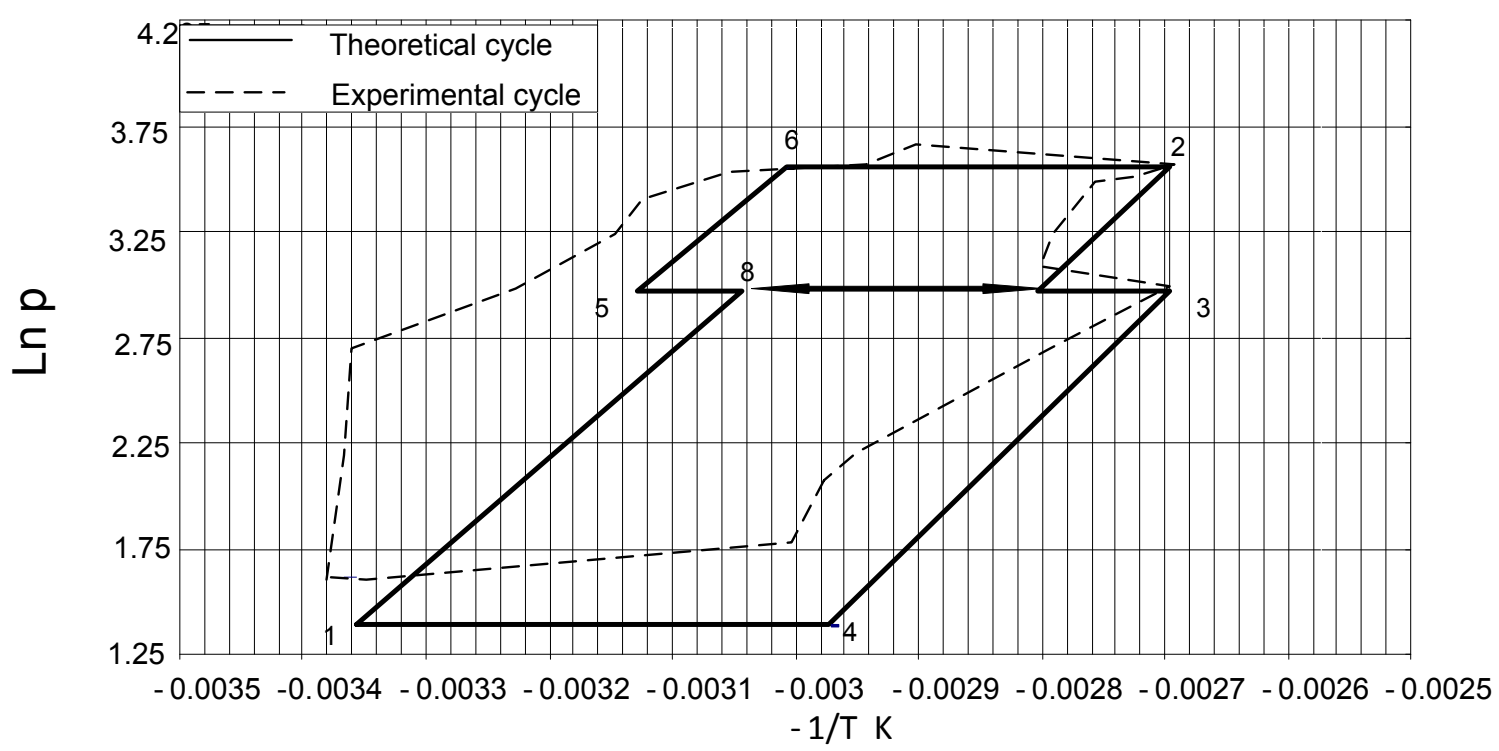

Figure 12. Comparison between the theoretical[13] and experimental P-T-X or Clapeyron diagram cycle 